\title{
How Mental Illness is Perceived by Iranian Medical Students: A Preliminary Study
}

\author{
Homayoun Amini ${ }^{\mathrm{a}, \mathrm{b}, *}$, Reza Majdzadeh ${ }^{\mathrm{c}, \mathrm{d}}$, Hasan Eftekhar-Ardebili ${ }^{\mathrm{d}, \mathrm{e}}$, Amir Shabani ${ }^{\mathrm{f}}$ and Rozita \\ Davari-Ashtiani ${ }^{\mathrm{g}}$
}

\author{
${ }^{a}$ Department of Psychiatry, Roozbeh Hospital, Tehran University of Medical Sciences, Tehran, Iran \\ ${ }^{b}$ Psychiatry and Psychology Research Center, Tehran University of Medical Sciences, Tehran, Iran \\ ${ }^{c}$ Department of Epidemiology, School of Public Health, Tehran University of Medical Sciences, Tehran, Iran \\ ${ }^{d}$ Health Center for Community-Based Participatory Research, Tehran University of Medical Sciences, Tehran, Iran \\ ${ }^{e}$ Department of Health Management, School of Public Health, Tehran University of Medical Sciences, Tehran, Iran \\ ${ }^{f}$ Department of Psychiatry, Mental Health Research Center, Tehran University of Medical Sciences, Tehran, Iran \\ ${ }^{g}$ Department of Psychiatry, Imam Hosein Hospital, Shahid Beheshti University of Medical Sciences, Tehran, Iran
}

\begin{abstract}
The study aimed to assess medical students' attitudes toward mental illness following a 4-week psychiatry clerkship. All fifth-year medical students from three academic centers in Tehran were asked to participate in the study. They completed the questionnaire on the last day of their 4-week psychiatry clerkship. A self-administered questionnaire was used to examine participants' Attitudes Toward Mental Illness (ATMI). One hundred and sixty eight students completed the questionnaires ( $88.9 \%$ response rate). In general, the students had favorable attitudes toward mental illness at the end of their clerkship, with mean $( \pm$ SD) ATMI total score of $78.6( \pm 8.1)$ (neutral score, 66.0). The students showed the most favorable opinion (95.2\%) about Category 5 (stereotypic attitude toward people with mental illness) whilst they revealed the least favorable opinion (64.3\%) regarding Category 1 (social relations with people affected by mental illness). In addition, the students thought that movies were on the top of influential media on shaping the attitudes toward mental illness. Overall, most of Iranian medical students had generally favorable attitudes toward people with mental illness at the end of their clerkship. Therefore, it may be expected next generation of medical doctors show more favorable attitude toward mental illness.
\end{abstract}

Keywords: Attitude, health personnel, medical students, mental disorders, public opinion, population.

\section{INTRODUCTION}

A substantial amount of research carried out in diverse cultures delineating attitudes towards mental illness held by general population, mental health professional, and patients' relatives [15]. These studies generally show that people with mental illness are perceived as different from patients with medical condition, frequently stereotyped as suspicious, dangerous, and violent [13]. Unfavorable people's interaction with people affected by mental illness may be an unwanted consequence of such negative attitudes. The intolerable attitudes of the health care personnel toward people with mental illness need attention since this might form a barrier for patients to receive appropriate care $[6,7]$. Despite efforts to try to change opinions about mental illness by individuals, groups, or organizations such as the World Health Organization, it still exists $[8,9]$.

Generally, public attitude toward mental illness may be mediated by various factors consisted of demographic

*Address correspondence to this author at the Department of Psychiatry, Roozbeh Hospital, South Kargar Avenue, Tehran 13337 95914, Iran;

Tel: +98 215541 2222; Fax: +98 215541 9113;

E-mail: aminihom@tums.ac.ir variables, socio-cultural factors, familiarity with mental illness, and sources of publicity $[1,2,10-13]$. Specifically, several factors may influence medical students' attitude toward mental illness such as teaching methods, educational atmosphere, medical training environment, role models, and direct patient care, as well [13-21].

However, medical students' attitude toward mental illness may be varying among different societies and cultures. However, there is some evidence regarding knowledge and attitude of public and health care provider toward mental health in Iran [22], to best our knowledge there is paucity about Iranian medical students' attitude toward "mental illness" as a general concept not a specific disorder. Therefore, we designed the present study as a preliminary one to assess medical students' attitudes toward mental illness following a 4-week psychiatry clerkship at teaching hospitals, affiliated in three schools of medicine in Tehran, Capital of Iran.

\section{SUBJECTS AND METHODOLOGY}

\subsection{Study Design}

All fifth-year medical students from three academic centers, Roozbeh (mental) Hospital, Iran (mental) Hospital, and 
Table 1. Medical Students' Attitude Toward Social Relations in Patients with Mental Illness (Category 1)

\begin{tabular}{|c|c|c|c|c|c|c|}
\hline Tt & Opinion & Strongly Disagree & Disagree & No Opinion & Agree & Strongly Agree \\
\hline 1 & $\begin{array}{l}\text { I'm ready to live in the same place with a men- } \\
\text { tally ill patient who has been hospitalized before } \\
\text { and now gets well }\end{array}$ & $\begin{array}{c}18 \\
(10.7)\end{array}$ & $\begin{array}{c}60 \\
(35.7)\end{array}$ & $\begin{array}{c}52 \\
(31)\end{array}$ & $\begin{array}{c}26 \\
(15.5)\end{array}$ & $\begin{array}{c}12 \\
(7.1)\end{array}$ \\
\hline 6 & $\begin{array}{l}\text { It's necessary to cut all the relationships of a } \\
\text { patient with mental illness with the society }\end{array}$ & $\begin{array}{c}91 \\
(54.2)\end{array}$ & $\begin{array}{c}68 \\
(40.5)\end{array}$ & $\begin{array}{c}5 \\
(3)\end{array}$ & $\begin{array}{c}2 \\
(1.2)\end{array}$ & $\begin{array}{c}2 \\
(1.2)\end{array}$ \\
\hline 7 & $\begin{array}{l}\text { If anyone of my relatives suffers from mental } \\
\text { illness, I'll be ready to go to a party or to go on a } \\
\text { trip with him/her }\end{array}$ & $\begin{array}{c}2 \\
(1.2)\end{array}$ & $\begin{array}{c}28 \\
(16.7)\end{array}$ & $\begin{array}{c}49 \\
(29.2)\end{array}$ & $\begin{array}{c}72 \\
(42.9)\end{array}$ & $\begin{array}{c}17 \\
(10.1)\end{array}$ \\
\hline 13 & $\begin{array}{l}\text { If anyone of my close relatives is mentally ill and } \\
\text { his/her doctor tells me that there is no danger, I'll } \\
\text { be ready to take care of him/her at home }\end{array}$ & $\begin{array}{l}5 \\
(3)\end{array}$ & $\begin{array}{c}24 \\
(14.3)\end{array}$ & $\begin{array}{c}35 \\
(20.8)\end{array}$ & $\begin{array}{c}76 \\
(45.2)\end{array}$ & $\begin{array}{c}28 \\
(16.7)\end{array}$ \\
\hline 20 & $\begin{array}{l}\text { I'm ready to be a close friend to a patient with } \\
\text { mental illness }\end{array}$ & $\begin{array}{c}23 \\
(13.7)\end{array}$ & $\begin{array}{c}51 \\
(30.4)\end{array}$ & $\begin{array}{c}61 \\
(36.3)\end{array}$ & $\begin{array}{c}23 \\
(13.7)\end{array}$ & $\begin{array}{l}10 \\
(6)\end{array}$ \\
\hline
\end{tabular}

Imam Hosein (general) Hospital affiliated in Tehran, Iran, and Shahid Beheshti Universities of Medical Sciences were asked to participate in the study. They completed the questionnaire on the last day of their 4-week psychiatry clerkship. A cover letter enclosed to the questionnaire explained to the students the purpose of the study and stated that student participation was purely voluntary and that all responses would be confidential and anonymous. It was explicitly declared that their responses would have no influence on their clerkship grades. Students were asked to answer the questionnaire during some academic session and not to discuss the statements among themselves to stay away from peer group influence. The study was approved by the ethics committee of Tehran University of Medical Sciences (TUMS).

\subsection{Participants}

Between February, 2009, and July, 2009, 189 medical students who were invited to participate in the study.

\subsection{Measure}

A self-administered questionnaire was used. The questionnaire was composed of two parts. The first part consisted of the questions about background information on specific subjects. Background information consisted of participant age, gender, rotation site, and history of personal contact with mentally ill patient, training environment, and perceived media role.

The second part examined participants' Attitudes Toward Mental Illness (ATMI). This part was adopted from two questionnaires and was validated and used in other studies in Iran [23-27]. The questionnaire consisted of 22 items divided into five categories: 1) attitude toward social relations in people with mental illness (six questions), 2) willingness to self-disclosure regarding mental illness (three questions), 3) attitude toward treatment of mental illness (six questions), 4) attitude toward etiology of mental illness (three questions), and 5) stereotypic attitude toward people with mental illness (four questions). The scoring was on a five-point Likert scale from 1 (strongly disagree) to 5 (strongly agree) with a higher score suggesting a more favorable attitude. The scoring on some of the items was reversed to avoid response bias. To establish content validity of the Persian version of ATMI, the questions were adapted based on the opinions of five experts (four psychiatrists and a clinical psychologist) and was adjusted in terms of social and cultural conditions. The internal consistency of the questionnaire, measured using Cronbach's alpha, was 0.86 .

\subsection{Data Analysis}

Data were analyzed using the Statistical Package for the Social Sciences (SPSS, V.16). The student's t tests and oneway ANOVA were used to examine the difference ATMI score between two genders and across different schools, respectively. Correlation analyses were computed by using Pearson correlation coefficients.

\section{RESULTS}

One hundred and sixty eight students completed the questionnaires $(88.9 \%$ response rate). Mean $( \pm \mathrm{SD})$ age of the participants was $23.8( \pm 1.8)$ years and $95(56.9 \%)$ were female.

In general, the students had favorable attitudes toward mental illness at the end of their clerkship, with mean $( \pm$ SD) ATMI total score of $78.6( \pm 8.1)$ (neutral score, 66.0). Only $11(6.6 \%)$ students scored lower than 66.0 and $153(92.2 \%)$ reported score higher than 66.0. There was no correlation between age and ATMI total score (Pearson correlation = $0.023, \mathrm{n}=165, \mathrm{p}=0.77)$. A comparison of the scores for men and women revealed no differences in term of the mean $( \pm$ SD) ATMI total score (men $77.76( \pm 9.52)$, women 79.16 $( \pm 6.91) ; \mathrm{t}=1.095, \mathrm{df}=163, \mathrm{p}=0.28)$.

Table 1 summaries the medical students' responses to the items relevant to social relations with people affected by 
Table 2. Medical Students' Attitude Toward Willingness to Self-Disclosure Regarding Mental Illness (Category 2)

\begin{tabular}{|c|c|c|c|c|c|c|}
\hline \multirow{2}{*}{ Item. No } & \multirow{2}{*}{ Opinion Item } & Strongly Disagree & Disagree & No Opinion & Agree & Strongly Agree \\
\hline & & $\mathbf{N}(\%)$ & N (\%) & N (\%) & N (\%) & N (\%) \\
\hline 2 & $\begin{array}{l}\text { I'll feel ashamed if anyone of my close } \\
\text { relatives is mentally ill }\end{array}$ & $\begin{array}{c}39 \\
(23.2)\end{array}$ & $\begin{array}{c}85 \\
(50.6)\end{array}$ & $\begin{array}{c}28 \\
(16.7)\end{array}$ & $\begin{array}{c}14 \\
(8.3)\end{array}$ & $\begin{array}{c}2 \\
(1.2)\end{array}$ \\
\hline 8 & $\begin{array}{l}\text { If anyone of my relatives suffers from } \\
\text { mental illness, I'll be ready to talk about } \\
\text { him/her with my friends }\end{array}$ & $\begin{array}{c}9 \\
(5.4)\end{array}$ & $\begin{array}{c}38 \\
(22.6)\end{array}$ & $\begin{array}{c}39 \\
(23.2)\end{array}$ & $\begin{array}{c}69 \\
(41.1)\end{array}$ & $\begin{array}{c}13 \\
(7.7)\end{array}$ \\
\hline 15 & $\begin{array}{l}\text { If I myself suffer from a mental illness, } \\
\text { I'll declare it }\end{array}$ & $\begin{array}{c}9 \\
(5.4)\end{array}$ & $\begin{array}{c}40 \\
(23.8)\end{array}$ & $\begin{array}{c}36 \\
(21.4)\end{array}$ & $\begin{array}{c}64 \\
(38.1)\end{array}$ & $\begin{array}{c}19 \\
(11.3)\end{array}$ \\
\hline
\end{tabular}

Table 3. Medical Students' Attitude Toward Treatment of Mental Illness (Category 3)

\begin{tabular}{|c|c|c|c|c|c|c|}
\hline Item. No & Opinion Item & Strongly Disagree & Disagree & No Opinion & Agree & Strongly Agree \\
\hline 3 & $\begin{array}{l}\text { The best treatment for patients with } \\
\text { mental illness is to move to a place with } \\
\text { a better climate }\end{array}$ & $\begin{array}{c}13 \\
(7.7)\end{array}$ & $\begin{array}{c}39 \\
(23.2)\end{array}$ & $\begin{array}{c}71 \\
(42.3)\end{array}$ & $\begin{array}{c}40 \\
(23.8)\end{array}$ & $\begin{array}{c}5 \\
(3)\end{array}$ \\
\hline 9 & Patients with mental illness are treatable & $\begin{array}{c}1 \\
(0.6)\end{array}$ & $\begin{array}{c}6 \\
(3.6)\end{array}$ & $\begin{array}{c}22 \\
(13.1)\end{array}$ & $\begin{array}{c}105 \\
(62.5)\end{array}$ & $\begin{array}{c}34 \\
(20.2)\end{array}$ \\
\hline 10 & $\begin{array}{l}\text { Marriage is an advantage for mentally } \\
\text { ill patients }\end{array}$ & $\begin{array}{c}13 \\
(7.7)\end{array}$ & $\begin{array}{c}46 \\
(27.4)\end{array}$ & $\begin{array}{l}79 \\
(47)\end{array}$ & $\begin{array}{c}25 \\
(14.9)\end{array}$ & $\begin{array}{c}5 \\
(3)\end{array}$ \\
\hline 16 & $\begin{array}{l}\text { If I myself suffer from a mental illness, } \\
\text { I refer to a psychiatrist }\end{array}$ & $\begin{array}{c}9 \\
(5.4)\end{array}$ & $\begin{array}{c}11 \\
(6.5)\end{array}$ & $\begin{array}{c}17 \\
(10.1)\end{array}$ & $\begin{array}{c}78 \\
(46.4)\end{array}$ & $\begin{array}{c}53 \\
(31.5)\end{array}$ \\
\hline
\end{tabular}

mental illness (Category 1). We found 108 (64.3\%) of the students had favorable attitudes toward this dimension with score higher than 18 (neutral score of Category 1 ); however, $48(28.6 \%)$ of the students showed unfavorable attitude with score lower than 18 .

The results of items related to willingness to selfdisclosure regarding mental illness (Category 2) are shown in Table 2. Most of medical students reported positive opinion in Category 2 with regard to $115(68.6 \%)$ of the students scored higher than 9 (neutral score of Category 2) as compared to $33(19.6 \%)$ of them who scored lower than 9.

Table 3 gives the medical students' responses to the items relevant to treatment of mental illness (Category 3 ). It is found $148(89.2 \%)$ of the students had favorable attitudes toward this dimension with regard to score higher than 18 (neutral score of Category 3); however, 9 (5.4\%) of the students reported unfavorable attitude with regard to the score lower than 18 .

Table 4 highlights the results of the items pertinent to etiology of mental illness (Category 4). It revealed 128 $(76.2 \%)$ of the students showed positive view of etiology of mental illness regarding their score of higher than 9 (neutral score of Category 4) even though 20 (11.9\%) of them showed negative view pertaining to their score lower than 9 .
Medical students' responses to the items relevant to stereotypic attitude toward people with mental illness (Category 5) are shown in Table 5. We found 160 (95.2\%) of the students had score higher than 12 (neutral score of Category 5) indicating not having negative stereotypic attitude toward people with mental illness as compared to only two $(1.2 \%)$ students who had score lower than 12.

One-way ANOVA revealed no significant difference across schools in terms of ATMI total score $(\mathrm{F}=0.394, \mathrm{df}=$ $2, \mathrm{p}=0.68)$. The mean $( \pm \mathrm{SD})$ total score on ATMI for students who trained at mental hospitals (Roozbeh or Iran Hospital) and for those who trained at a general hospital (Imam Hosein Hospital) were $78.32( \pm 8.52)$ and $79.64( \pm 6.43)$, respectively. The difference between two groups was not significant $(\mathrm{t}=-0.865, \mathrm{df}=164, \mathrm{p}=0.39)$.

Forty eight $(28.6 \%)$ of the medical students reported close personal contacts with people affected by mental illness before entering psychiatry clerkship as compared to 86 $(51.2 \%)$ of those who never had such experiences; however, when the mean $( \pm \mathrm{SD})$ on ATMI total score compared between two groups, the difference was not statistically significant $(79.63( \pm 6.89)$ vs. $78.59( \pm 8.42)$, respectively; $\mathrm{t}=$ $0.724, \mathrm{df}=132, \mathrm{p}=0.47)$. 
Table 4. Medical Students' Attitude Toward Etiology of Mental Illness (Category 4)

\begin{tabular}{|c|c|c|c|c|c|c|}
\hline \multirow{2}{*}{ Item. No } & \multirow{2}{*}{ Opinion Item } & Strongly Disagree & Disagree & No Opinion & Agree & Strongly Agree \\
\hline & & N (\%) & N (\%) & N (\%) & $\mathbf{N}(\%)$ & N (\%) \\
\hline 4 & $\begin{array}{l}\text { The close relatives } \mathrm{f} \text { patients with mental } \\
\text { illness will be affected by this kind of illness }\end{array}$ & $\begin{array}{c}8 \\
(4.8)\end{array}$ & $\begin{array}{c}28 \\
(16.7)\end{array}$ & $\begin{array}{c}35 \\
(20.8)\end{array}$ & $\begin{array}{c}89 \\
(53)\end{array}$ & $\begin{array}{c}8 \\
(4.8)\end{array}$ \\
\hline 11 & $\begin{array}{l}\text { Mental illness is caused by fairies and meta- } \\
\text { physical creatures }\end{array}$ & $\begin{array}{c}118 \\
(70.2)\end{array}$ & $\begin{array}{c}32 \\
(19)\end{array}$ & $\begin{array}{c}15 \\
(8.9)\end{array}$ & $\begin{array}{c}1 \\
(0.6)\end{array}$ & $\begin{array}{c}2 \\
(1.2)\end{array}$ \\
\hline 17 & $\begin{array}{l}\text { Accompanying a patient with mental illness } \\
\text { may make me mentally ill }\end{array}$ & $\begin{array}{c}40 \\
(23.8)\end{array}$ & $\begin{array}{c}62 \\
(36.9)\end{array}$ & $\begin{array}{c}33 \\
(19.6)\end{array}$ & $\begin{array}{c}31 \\
(18.5)\end{array}$ & $\begin{array}{c}2 \\
(1.2)\end{array}$ \\
\hline
\end{tabular}

Table 5. Medical Students' Stereotypic Attitude Toward Patients with Mental Illness (Category 5)

\begin{tabular}{|c|c|c|c|c|c|c|}
\hline Item. No & Opinion Item & Strongly Disagree & Disagree & No Opinion & Agree & Strongly Agree \\
\hline 5 & $\begin{array}{l}\text { All patients with mental illness must be taken } \\
\text { care of in hospitals }\end{array}$ & $\begin{array}{c}51 \\
(30.4)\end{array}$ & $\begin{array}{c}96 \\
(57.1)\end{array}$ & $\begin{array}{c}12 \\
(7.1)\end{array}$ & $\begin{array}{c}7 \\
(4.2)\end{array}$ & $\begin{array}{c}2 \\
(1.2)\end{array}$ \\
\hline 12 & Mental illnesses are all of the same kind & $\begin{array}{c}88 \\
(52.4)\end{array}$ & $\begin{array}{c}70 \\
(41.7)\end{array}$ & $\begin{array}{c}6 \\
(3.6)\end{array}$ & $\begin{array}{c}3 \\
(1.8)\end{array}$ & $\begin{array}{c}1 \\
(0.6)\end{array}$ \\
\hline 19 & All patients with mental illness are dangerous & $\begin{array}{c}54 \\
(32.1)\end{array}$ & $\begin{array}{c}97 \\
(57.7)\end{array}$ & $\begin{array}{c}9 \\
(5.49)\end{array}$ & $\begin{array}{c}6 \\
(3.6)\end{array}$ & $\begin{array}{c}2 \\
(1.2)\end{array}$ \\
\hline
\end{tabular}

Table 6. Medical Students' Perceived Influence of Media on their Attitudes Toward Mental Illness before Psychiatry Clerkship $(1=$ the Least, 7 = the Most)

\begin{tabular}{|c|c|c|c|c|}
\hline Statistic Media & Mean & Std. Deviation & Median & Mode \\
\hline \hline Movies & 4.16 & 2.77 & 3.0 & 7.0 \\
\hline TV/Radio educational programs & 3.35 & 2.39 & 3.0 & 1.0 \\
\hline Newspapers /Magazines & 3.28 & 2.16 & 3.0 & 1.0 \\
\hline TV/Radio NEWS & 3.04 & 2.21 & 2.0 & 1.0 \\
\hline Other books & 3.01 & 2.41 & 2.0 & 1.0 \\
\hline Novels & 2.80 & 2.20 & 1.5 & 1.0 \\
\hline Radio stories & 2.46 & 2.22 & & 1.0 \\
\hline
\end{tabular}

Table 6 summaries the students' responses to perceived influence of media on their opinions about mental illness. As it is shown, the students thought that movies were on the top of influential media on shaping the attitudes toward mental illness.

\section{DISCUSSION}

The study aimed to examine Iranian medical students' attitudes toward mental illness after psychiatry clerkship. In general more than $92 \%$ of the students had favorable attitudes toward people with mental illness at the end of their clerkship; however, there was diversity across different categories of ATMI. The students showed the most favorable opinion (95.2\%) about Category 5 (stereotypic attitude toward people with mental illness) whilst they revealed the least favorable opinion (64.3\%) regarding Category 1 (social relations with people affected by mental illness).

\subsection{Category 1 (Social Relations with People Affected by Mental Illness)}

In spite of overall optimism of Iranian medical students about people with mental illness, they showed intolerant attitude toward close relationships with this people. Only one-fourth of the students stated that would be ready to live or work in the same place with a person with mental illness and less than one-fifth of them would be ready to be a close friend to a patient with mental illness. In other studies, 51.8$60.3 \%$ of medical students did not accept to be willing to work on a job with former patients $[18,28]$ whilst only $9.6 \%$ of the students accepted to be willing to rent a room in their 
home to former patients [18] and $51.9 \%$ of the students would not accept a former mental patient as a close friend [28]. Considering unfavorable students' attitudes concerning social relations with people affected by mental illness that can potentially influence patient-physician relationship at the future, it is essential that continued efforts devoted to find some ways to improve the students' views of this category.

\subsection{Category 2 (Willingness to Self-Disclosure Regarding Mental Illness)}

The present study revealed that $73.8 \%$ of the students declared they disagreed with the item "I'll feel ashamed if anyone of my close relatives is mentally ill". In a study in Japan, $38.6 \%$ of the medical students showed similar opinion [18]. It could indicate that Iranian society may be more tolerant than some other Eastern countries.

\subsection{Category 3 (Treatment of Mental IIIness)}

Around $80 \%$ of students in our study thought people with mental illness are treatable and medications are effective in treating people with mental illness. Other studies reported less favorable opinion about treatment of people with mental illness in medical students and doctors $[18,28]$. It could indicate that Iranian tomorrow's doctors may have more positive opinion about psychiatric treatment than their counterparts in some other Eastern countries.

\subsection{Category 4 (Etiology of Mental Illness)}

Contrary to the result of other studies from Middle East and Africa [28, 29], beliefs in supernatural causes of mental illness was rare among Iranian medical students. Although we did not directly evaluate biogenetic causal attributions of mental illness among the medical students, their response to the questions 4 and 17 may indirectly indicate the kind of attribution. Therefore, it may be assumed that most of the students had biogenetic causal attributions of mental illness. However, it is expected that biological or genetic models of mental illness may increase tolerance towards people with mental illness by reducing the stigma and rejection, two recent reviews concluded that biogenetic causal models were not associated with more tolerant attitudes or better social acceptance [30, 31].

\subsection{Category 5 (Stereotypic Attitude Toward People with Mental IIlness)}

The majority of students in the present study disagreed with that all patients with mental illness must be taken care of in hospitals; however, the medical students were trained in teaching hospitals rather than community-based services. This view is comparable to Mino and colleagues (2000) [18] but it is in contrast with dominant opinion of students from other country who stated that facilities for mental health care should be located away from the community [29]. Also, less than $5 \%$ of Iranian medical students considered people with mental illness as dangerous. It is noticeably less than those reported by Adewuya and Oguntade (2007) of 70.5\% [28].

In general, as Jorm and colleagues (1997) found that younger members of health professionals tend take a broader view about mental illness [32] and it may represent a possible cohort effect, Iranian medical students showed favorable attitude toward mental illness.

\subsection{Mental Hospital vs. General Hospital}

To our best knowledge, there is no published study on influence of psychiatry clerkship at a mental hospital compared to a general hospital on students' attitude toward mental illness. However, it is found that the effect of hospital experience may be positive or negative depending on the environment atmosphere where experience occurs [33, 34].

\subsection{Close Personal Contact with People with Mental Ill- ness before Entering Clerkship}

We found no relationship between close personal contacts with people affected by mental illness before clerkship/or direct experience with a family member with mental illness and attitude toward mental illness. Our finding was in line with some previous studies [29, 35-37]; however, several studies are shown personal contact with people affected by mental illness might positively influence attitude of public, generally, and students, specifically, toward mental illness [28, 38-45].

\subsection{Age}

We found no association between age and ATMI total score. This finding was in keeping with the finding of several studies in general population $[2,41]$ and in medical students [29] but discordant with the results of other studies in general population $[2,39]$. It may be due to narrow variance of age variable among medical students because they come from the same cohort.

\subsection{Gender}

According to the present study, there was no difference between two genders in terms of ATMI total score. Angermeyer and Dietrich (2006) in a review showed that the results of previous studies concerning influence of gender on public's attitude toward mental illness are quite inconsistent [2]. In a recent systematic review of population-based studies, Holzinger and colleagues (2012) concluded that women do not seem to display more positive attitudes than men towards people with mental illness, with a few exceptions. Women are more likely to approve psychosocial approach to mental illness than men and it also seems that women are more ready to suggest professional help than men [46]. In line with our finding in medical students, Al-Adawi and colleagues (2002) found no association between students' attitudes toward mental illness and gender [29]; however, greater social distance was associated with female gender in medical students in another study [42].

\subsection{Students' Perceptions about Influence of Media on their Attitudes Toward Mental Illness Before Entering}

The present study showed that the medical students thought that movies were on the top of influential media on shaping their attitudes toward mental illness. We did not find similar studies to be able to compare our result with them. However, the present study could not determine to which direction and how much students' attitudes have been influenced by media, specifically movies, and then, to how much psychiatry clinical rotation could change pre-clerkship attitudes toward mental illness. 


\subsection{Limitations and Implications}

The results of present study should be interpreted in the light of its limitations. We did not assess the medical students' attitude toward mental illness before entering psychiatry rotation. Thus, it was not possible to evaluate influence of our psychiatry clerkship on Iranian medical students' opinion about mental illness. Moreover, the findings of the present study might be influenced by the students' attitude before entering clerkship. If the students had more favorable attitudes before the course, their attitudes could have been less influenced by passing the clerkship. The results of previous studies concerning impact of psychiatry rotation on attitude toward mental illness are inconsistent. Several studies are shown positive effect of psychiatry rotation on medical students' opinion about mental illness [14, 18, 35, 47]; however, the findings of other studies showed no impact [37, $48,49]$. It is proposed that a future study could be done to compare medical students' attitude toward mental illness before and after a clinical course in psychiatry, not only by using observational design but also by conducting interventional design to explore new methods that may influence students' attitude more, and to compare with a control group. In addition, a longitudinal study would be better to assess the impact of any educational intervention on the medical students' attitude of mental illness and on their future professional behavior in real practice, as the same sample would then be followed up over a longer period.

Another limitation of present study is the absence of follow-up to see if positive attitudes toward mental illness remain over time. As Baxter and colleagues (2001) showed the positive change that takes place in medical students' attitude towards mental illness after psychiatry training may be transient and decay over the time [50]. Thus, longitudinal studies should be appreciated to assess the persistence of favorable attitude toward mental illness.

As Singh and colleagues (1998) mentioned questionnaire per se may not truly assess attitudes and its impacts on behavior in real practice since students may give responses that are supposed to give a correct impression of themselves [14]. Moreover, there is diversity across different studies regarding measures using to assess attitude toward mental illness. In addition, these measures are divided into diverse categories; however, many inter-connections exist between the categories, and there is sometimes obscurity in judging which is the most suitable to use in categorizing a subscale [51]. In addition, the present study questionnaire could not differentiate students' attitude toward various mental illness such as schizophrenia and depression. It is possible there is diversity among medical students in terms of their opinion about different psychiatric disorders. There are other limitations such as small sample size, and confined to three schools that may cause inadequate power to detect possible associations between different variables and may not to generalize the study results to all Iranian medical students, respectively.

\section{CONCLUSIONS}

Overall, most of Iranian medical students had generally favorable attitudes toward people with mental illness at the end of their clerkship. The students showed the most favor- able opinion about stereotypic belief concerning people with mental illness whilst they revealed the least favorable opinion regarding social relation with people affected by mental illness. Therefore, it may be expected next generation of medical doctors show more favorable attitude toward mental illness. However, considering unfavorable attitudes concerning social relations with people affected by mental illness in a considerable percentage of Iranian students, it is essential that continued efforts devoted to find some ways to improve the students' opinions about social relations with people with mental illness. Further longitudinal studies should be appreciated to assess the persistence of favorable attitude toward mental illness over the time.

\section{CONFLICT OF INTEREST}

The authors confirm that this article content has no conflicts of interest.

\section{ACKNOWLEDGEMENTS}

This study was supported by Tehran University of Medical Sciences. We thank Dr. Maryam Tabatabaee, Mrs. Fattaneh Abdi, and Mrs. Fatemeh Rovhani who helped with administration of the project. We also wish to thank all medical students who participated in this project.

\section{REFERENCES}

[1] Rabkin JG. Opinions about mental illness: a review of the literature. Psychol Bull 1972; 77: 153-71.

[2] Angermeyer MC, Dietrich S. Public beliefs about and attitudes towards people with mental illness: a review of population studies. Acta Psychiatr Scand 2006; 113: 163-79.

[3] Angermeyer MC, Holzinger A, Matschinger H. Mental health literacy and attitude towards people with mental illness: a trend analysis based on population surveys in the eastern part of Germany. Eur Psychiatry 2009; 24: 225-32.

[4] Bhugra D. Attitudes towards mental illness. Acta Psychiatr Scand 1989; 80: 1-12.

[5] Premalatha Chinnayya H, Chandrashekar CR, Moily S, et al. Training primary care health workers in mental health evaluation of attitudes towards mental illness before and after training. Int $\mathrm{J}$ Soc Psychiatry 1990; 36: 300-7.

[6] Jugal K, Mukherjee R, Parashar M, Jiloha R, Ingle G. Beliefs and attitudes towards mental health among medical professionals in Delhi. Indian J Community Med 2007; 32: 198-200.

[7] Bolton J. How can we reduce the stigma of mental illness? BMJ 2003; 326: S57.

[8] Crisp AH. The stigmatization of sufferers with mental disorders. Br J Gen Pract 1999; 49: 3-4.

[9] Crisp AH, Gelder MG, Rix S, Meltzer HI, Rowlands OJ. Stigmatisation of people with mental illnesses. Br J Psychiatry 2000; 177: 4-7.

[10] Hayward, Jenifer A, Bright P. Stigma and mental illness: A review and critique. J Ment Health 1997; 6: 345-54.

[11] TNS. Attitudes to Mental Illness 2008 Research Report. London: Department of Health 2008.

[12] Abdullah T, Brown TL. Mental illness stigma and ethnocultural beliefs, values, and norms: An integrative review. Clin Psychol Rev 2011; 31: 934-48.

[13] Shokoohi-Yekta M, Retish PM. Attitudes of Chinese and American male students towards mental illness. Int J Soc Psychiatry 1991; 37: 192-200.

[14] Singh SP, Baxter H, Standen P, Duggan C. Changing the attitudes of 'tomorrow's doctors' towards mental illness and psychiatry: a comparison of two teaching methods. Med Educ 1998; 32: 115-20.

[15] Spiegel DA. Motivating the student in the psychiatry clerkship. J Med Educ 1981; 56: 593-600.

[16] Ay P, Save D, Fidanoglu O. Does stigma concerning mental disorders differ through medical education? A survey among medical 
students in Istanbul. Soc Psychiatry Psychiatr Epidemiol 2006; 41: 63-7.

[17] Coodin S, Chisholm F. Teaching in a new key: effects of a cotaught seminar on medical students' attitudes toward schizophrenia. Psychiatr Rehabil J 2001; 24: 299-302.

[18] Mino Y, Yasuda N, Kanazawa S, Inoue S. Effects of medical education on attitudes towards mental illness among medical students: a five-year follow-up study. Acta Med Okayama 2000; 54: 127-32.

[19] Mino Y, Yasuda N, Tsuda T, Shimodera S. Effects of a one-hour educational program on medical students' attitudes to mental illness. Psychiatry Clin Neurosci 2001; 55: 501-7.

[20] Holmes EP, Corrigan PW, Williams P, Canar J, Kubiak MA. Changing attitudes about schizophrenia. Schizophr Bull 1999; 25: 447-56.

[21] Mukherjee R, Fialho A, Wijetunge A, Checinski K, Surgenor T. The stigmatization of psychiatric illness the attitudes of medical students and doctors in a London teaching hospital. Psychiatr Bull 2002; $26: 178-81$.

[22] Mansouri N, Gharaee B, Shariat SV, et al. The change in attitude and knowledge of health care personnel and general population following trainings provided during integration of mental health in Primary Health Care in Iran: a systematic review. Int J Ment Health Syst 2009; 3: 15 .

[23] Cohen J, Struening EL. Opinions about mental illness in the personnel of two large mental hospitals. J Abnorm Soc Psychol 1962; 64: 349-60.

[24] Crocetti G, Spiro HR, Siassi I. Are the ranks closed? Attitudinal social distance and mental illness. Am J Psychiatry 1971; 127: 1121-7.

[25] Ghasemi A, Fatemi MM. [The effect of an educational film on the attitudes of mentally ill patients' families toward mental illness]. (in Persian). MD dissertation. Tehran: Tehran University of Medical Sciences 1999.

[26] Pezeshki-Ghahfarokhi Z. [Attitude toward mental illness in several rural areas in the North of Tehran]. (in Persian). MSc dissertation. Tehran: Tehran University of Medical Sciences 1987.

[27] Kheirabadi G, Yousefi F, Vafaei F. [Attitude toward mental illness in Sanandaj]. (in Persian). Sci J Kurdistan Univ Med Sci 1997; 2: 14-7.

[28] Adewuya AO, Oguntade AA. Doctors' attitude towards people with mental illness in Western Nigeria. Soc Psychiatry Psychiatr Epidemiol 2007; 42: 931-6.

[29] Al-Adawi S, Dorvlo AS, Al-Ismaily SS, et al. Perception of and attitude towards mental illness in Oman. Int J Soc Psychiatry 2002; 48: 305-17.

[30] Angermeyer MC, Holzinger A, Carta MG, Schomerus G. Biogenetic explanations and public acceptance of mental illness: systematic review of population studies. Br J Psychiatry 2011; 199: 36772.

[31] Schomerus G, Schwahn C, Holzinger A, et al. Evolution of public attitudes about mental illness: a systematic review and metaanalysis. Acta Psychiatr Scand 2012; 125: 440-52.

[32] Jorm AF, Korten AE, Jacomb PA, Rodgers B, Pollitt P. Beliefs about the helpfulness of interventions for mental disorders: a comparison of general practitioners, psychiatrists and clinical psychologists. Aust N Z J Psychiatry 1997; 31: 844-51.
[33] Boey KW. Medical students' attitudinal change associated with mental hospital experience. Singapore Med J 1985; 26: 45-8.

[34] Jaffe Y, Maoz B, Avram L. Mental hospital experience, classroom instruction and change in conceptions and attitudes towards mental illness. Br J Med Psychol 1979; 52: 253-8.

[35] Mas A, Hatim A. Stigma in mental illness: attitudes of medical students towards mental illness. Med J Malaysia 2002; 57: 433-44.

[36] Arkar H, Eker D. Influence of having a hospitalized mentally ill member in the family on attitudes toward mental patients in Turkey. Soc Psychiatry Psychiatr Epidemiol 1992; 27: 151-5.

[37] Calvert SH, Sharpe M, Power M, Lawrie SM. Does undergraduate education have an effect on Edinburgh medical students' attitudes to psychiatry and psychiatric patients? J Nerv Ment Dis 1999; 187: 757-61.

[38] Angermeyer MC, Matschinger $\mathrm{H}$. The effect of personal experience with mental illness on the attitude towards individuals suffering from mental disorders. Soc Psychiatry Psychiatr Epidemiol 1996; 31: 321-6.

[39] Angermeyer MC, Matschinger H, Corrigan PW. Familiarity with mental illness and social distance from people with schizophrenia and major depression: testing a model using data from a representative population survey. Schizophr Res 2004; 69: 175-82.

[40] Arikan K, Uysal O. Emotional reactions to the mentally ill are positively influenced by personal acquaintance. Isr J Psychiatry Relat Sci 1999; 36: 100-4.

[41] Wolff G, Pathare S, Craig T, Leff J. Public education for community care. A new approach. Br J Psychiatry 1996; 168: 441-7.

[42] Chung KF, Chen EYH, Liu CSM. University Students' Attitudes Towards Mental Patients and Psychiatric Treatment. Int J Soc Psychiatry $2001 ; 47: 63-72$.

[43] Corrigan PW, Green A, Lundin R, Kubiak MA, Penn DL. Familiarity with and social distance from people who have serious mental illness. Psychiatr Serv 2001; 52: 953-8.

[44] Vezzoli R, Archiati L, Buizza C, Pasqualetti P, Rossi G, Pioli R. Attitude towards psychiatric patients: a pilot study in a northern Italian town. Eur Psychiatry 2001; 16: 451-8.

[45] Tharyan P, John T, Tharyan A, Braganza D. Attitudes of 'tomorrow's doctors' towards psychiatry and mental illness. Natl Med J India 2001; 14: 355-9.

[46] Holzinger A, Floris F, Schomerus G, Carta M, Angermeyer M. Gender differences in public beliefs and attitudes about mental disorder in western countries: A systematic review of population studies. Epidemiol Psychiatr Sci 2012; 21: 73-85.

[47] Mary Keane RN. Contemporary beliefs about mental illness among medical students: implications for education and practice. Acad Psychiatry 1990; 14: 172-7.

[48] Fabrega H Jr. Does a clerkship affect students' views of psychiatric patients? J Nerv Ment Dis 1995; 183: 736-42.

[49] Malla A, Shaw T. Attitudes Towards Mental Illness: the Influence of Education and Experience. Int J Soc Psychiatry 1987; 33: 33-41.

[50] Baxter H, Singh SP, Standen P, Duggan C. The attitudes of 'tomorrow's doctors' towards mental illness and psychiatry: changes during the final undergraduate year. Med Educ 2001; 35: 381-3.

[51] Brohan E, Slade M, Clement S, Thornicroft G. Experiences of mental illness stigma, prejudice and discrimination: a review of measures. BMC Health Serv Res 2010; 10: 80.

Received: December 31, 2012

Revised: March 03, 2013

Accepted: March 04, 2013

(c) Amini et al.; Licensee Bentham Open.

This is an open access article licensed under the terms of the Creative Commons Attribution Non-Commercial License (http://creativecommons.org/licenses/by-nc/3.0/) which permits unrestricted, non-commercial use, distribution and reproduction in any medium, provided the work is properly cited. 